\title{
The Assessment of End-Tidal Capnography Waveform Interpretation and Its Clinical Application for Emergency Residents in Malaysia: A Cross-Sectional Study
}

\author{
(D) Ri Church Chee ${ }^{1}$, (1) Rashidi Ahmad ${ }^{1}$, (1) Mohd Idzwan Zakaria ${ }^{1}$, (1) Mohammad Fadhly Yahya ${ }^{2}$
}

1Unit of Trauma and Emergency, University of Malaya Faculty of Medicine, Kuala Lumpur, Malaysia

2Department of Emergency and Trauma, Hospital Melaka, Melaka, Malaysia

\begin{abstract}
Aim: This study aimed to assess the adequacy of knowledge among emergency residents (ERs) and determine the correlation between the knowledge and practice of capnography waveform (CW).

Materials and Methods: This 6-month questionnaire-based cross-sectional study was conducted at the emergency department of a hospital. All ERs were included in this study. Respondents' knowledge was evaluated by exploring their interpretation of CW according to clinical situations and their ability in making appropriate clinical decisions and management. Pearson correlation statistic was used to determine the correlation between knowledge and practice.

Results: This study included 48 ERs. The mean scores for knowledge and practice ( \pm standard deviation) were $5.69 \pm 1.82$ and $4.40 \pm 1.8$, respectively. No correlation was found between knowledge and practice $(r=0.186, p=0.207)$.

Conclusion: ERs' ability to interpret CW was satisfactory. However, understanding the relevance of the CW findings and subsequent clinical management was poor.
\end{abstract}

Keywords: Emergency residents, capnography waveform, knowledge, practice

\section{Introduction}

End-tidal carbon dioxide $\left(\mathrm{EtCO}_{2}\right)$ is the concentration of carbon dioxide $\left(\mathrm{CO}_{2}\right)$ at the end of expiration. It provides information on ventilation $\left(\mathrm{CO}_{2}\right.$ elimination), perfusion $\left(\mathrm{CO}_{2}\right.$ transport in blood circulation), and metabolism (cellular metabolism and production of $\left.\mathrm{CO}_{2}\right)(1-5)$.

Capnography Waveform (CW) is a useful, non-invasive, reliable, and real-time monitoring tool in emergency settings that can improve patient safety. It has been used extensively and became a standard of care to monitor the patient's ventilation during procedural sedation and analgesia (6). Moreover, it allows the rapid detection of airway obstruction, hypoventilation, and apnea in real-time $(7,8)$. Henceforth, immediate intervention can be instituted early to prevent catastrophic consequences (9).

For patients with acute respiratory distress manifestations, clinical status, and CW findings provide essential clinical information. Abnormal CW is associated with higher intubation rates, intensive care unit (ICU) admissions, and mortality (10).

International Liaison Committee on Resuscitation recommended the application of quantitative waveform capnography during cardiopulmonary resuscitation (CPR) to ensure effective chest compression and to detect the return of spontaneous circulation $(11,12)$. Moreover, CW may provide an objective basis to determine patients' prognosis, hence, terminating CPR (13). Continuous 
CW is also considered the gold standard for verifying proper endotracheal tube placement (1-4).

However, this monitoring technology is only as good as the user who analyses and interprets it. The ability to accurately interpret the CW is important but appropriately acting on the finding is important as well. The purposes of this study were to assess the knowledge of emergency residents (ERs) on CW who use it in their daily clinical practice and to determine the correlation coefficient between the ability of interpreting $\mathrm{CW}$ and the appropriateness of clinical intervention following the interpretation. We postulated that the mean score of knowledge and practice in CW and its application among ERs is $50 \%$ to $60 \%$, and there is a significant positive correlation between knowledge and practice of CW.

We believe that knowledge and practice gap findings detected in this study can form a basis local education program development concerning the role of $\mathrm{CW}$ in clinical practice. The same questionnaire from this study can be utilized to evaluate the effectiveness of the education program.

\section{Materials and Methods}

\section{Study Design and Setting}

This questionnaire-based, cross-sectional study was conducted in the emergency department (ED), Hospital Melaka, Malaysia, over 6 months period that lasted from September 1 15t, 2019 to February $28^{\text {th }}, 2020$. Hospital Melaka is a tertiary hospital located in Melaka state, Malaysia, with multiple specialty disciplines and subspecialty service.

The number of ERsworking in ED Hospital Melaka was inconsistent due to hospital administrative allocation, availability of new residents, and request from ERs to transfer to other departments. ED Hospital Melaka was staffed with 30 ERs in the year 2018, 35 ERs in the year 2019, and 45 in the year 2020. Their experience in ED varies, ranging from 0 months to 6 years, with the majority less than 3 years in ED. To ensure competency and up-to-date medical knowledge, continuing medical education (CME) sessions were held weekly to discuss various emergency topics, in a traditional pedagogy approach aided with simple technology, e.g. PowerPoint slides presentation or video demonstration. Inevitably ERs will miss part of the CME sessions due to working shifts. From the year 2019, capnography was available in ED Hospital Melaka (Oridion ${ }^{\circledR}$ sidestream device for the intubated patient only). Summary of CW in different clinical scenarios was printed and attached on the wall next to monitoring devices in the resuscitation zone to aid clinical judgment of clinicians when interpreting CW.
This study was conducted in compliance with the ethical principles outlined in the Declaration of Helsinki and Malaysia Good Clinical Practice (GCP) Guideline.

\section{Population and Sample Size}

ERs in ED Hospital Melaka were recruited through universal sampling. The ERs who were on leave during the study period and did not complete the questionnaire were excluded from the study.

The sample size was calculated using Power Analysis and Sample Size Software (PASS) version 11.0 (NCSS, LLC, Kaysvillie UT, USA). Sample size calculation followed Bujang and Baharum's (14) recommendations to analyze the correlation between knowledge and practice. To achieve a significant result $(p<0.05)$ with sufficient power $(80 \%)$ and at least a correlation coefficient of 0.4 , the below formula was applied $(14,15)$.

Sample size $=N=\left[\left(Z_{\alpha}+Z_{\beta}\right) / C\right]^{2}$

The standard normal deviate for $\alpha=Z_{\alpha}=1.9600$

The standard normal deviate for $\beta=Z_{\beta}=0.8416$

$C=0.5 \times \ln [(1+r) /(1-r)]=0.4236$

$N=\left[\left(Z_{\alpha}+Z_{\beta}\right) / C\right]^{2}=42$

A $10 \%$ dropout rate was added to the total sample to get the required sample size. As a result, the total number of 48 respondents was required for inferential analysis. Respondents were approached personally by the author to improve the engagement in this study to ensure the dropout rate not exceeding the estimation of $10 \%$. Any confusion, doubts, and queries would be explained promptly, and the author would receive feedback directly after the questionnaire was answered.

\section{Research Tool Development}

We adapted The Association of Medical Education in Europe Guide no. 87 for educational research questionnaire development to formulate the questionnaire (16). The questionnaire construction process consists of five stages: item development, pretest, face validation, pilot study, and finalize questionnaire (16).

In the context of this study, knowledge is defined as the correct interpretation of CW tracing, and practice is defined as the correct management of patients based on the simulated clinical picture and end-tidal CW interpretation. The questionnaire was constructed with the concept of the minimally competent candidates (or "borderline candidates") to discriminate between candidates with and without adequate theoretical and applicable knowledge (17). 


\section{Stage 1: Item Development}

An extensive literature review was conducted using textbooks, PubMed, and Google Scholar. The term "end-tidal capnography waveform" is synonymous with "EtCO,", "waveform capnography", "end-tidal carbon dioxide", "capnography", "endtidal capnography" and "EtCO $\mathrm{CO}_{2}$ waveform monitoring". Existing questionnaires related to knowledge and practice towards endtidal capnography waveforms were sought. Core topics in $\mathrm{EtCO}_{2}$ were listed after interviews with emergency physicians and readings from journals, international guidelines, or consensus.

The knowledge section's core topics included normal waveform interpretations, indications of $\mathrm{EtCO}_{2}$ monitoring, and causes of flat line tracings. The practice section's core topics included the application of $\mathrm{EtCO}_{2}$ during CPR, mechanical ventilation, and pattern recognition of abnormal waveforms in different clinical scenarios.

\section{Stage 2: Pretest of the Draft Questionnaire}

Selected items were drafted into a questionnaire and pretested among 15 ERs. Interviews were conducted to check for comprehensiveness, readability, relevance, and clarity of the draft questionnaire. Feedbacks were considered, and corrections were made to the draft questionnaire.

\section{Stage 3: Face and Content Validation}

For face validation, a panel consisting of 6 experts in the field of end-tidal CW in the emergency setting was invited to validate the questionnaire $(18,19)$. They are emergency physicians or consultants who have clinical experience in end-tidal CW, education/training, or survey study.

The content validity index (CVI) was calculated for each item to decide its acceptability. Experts were asked to rate items for clarity, relevance, representativeness, and importance on a 4-point scale. For instance, to rate relevance of an item, experts are given four options: $1=$ not relevant, $2=$ somewhat relevant, 3 = quite relevant, $4=$ highly relevant (20). The scale-level content validity index (S-CVI/Ave) was calculated using the averaging calculation method. Ratings of more than 0.9 are considered excellent content validity (21). In this study, S-CVI/Ave score for both knowledge and practice was 0.9 and above.

\section{Stage 4: Pilot Study and Retest}

A pilot test was carried out among 15 ERs, and a retest was conducted a week after. The intraclass correlation coefficient (ICC) was used to test the reliability of the questionnaire. ICC values of less than 0.5 indicate poor reliability, values between 0.5 and 0.75 indicate moderate reliability, values between 0.75 and 0.9 indicate good reliability, and values greater than 0.90 indicate excellent reliability $(22,23)$. In this study, all the items achieved an ICC of more than 0.7 .

\section{Stage 5: Finalise Questionnaire}

The final questionnaire consists of six items in the demographics section, 10 items in the knowledge section, and 10 items in the practice section (Appendix 1).

\section{Data Collection}

The questionnaire was distributed among respondents who fulfilled the criteria and consented from September $1^{\text {st }}, 2019$ to February $28^{\text {th }}, 2020$. Respondents who were involved in the pretest and pilot study were excluded. They were required to answer all the items within one hour, without discussing or refer to any resources.

\section{Statistical Analysis}

Statistical analysis was performed using Statistical Package for the Social Science version 20.0 (SPSS Inc. Cary, NC, USA). The distribution of the data set was determined by evaluating skewness and kurtosis results. The skewness and kurtosis value within -1 to +1 were considered normal distribution of the data set. Numerical data were reported either as mean [standard deviation (SD)] or median [interquartile range (IQR)]. Categorical data were reported as a percentage (\%).

There were 10 items in the knowledge and practice section, respectively. One (1) mark would be given for the correct response in each item. The minimum score would be 0 , and the maximum score would be 10 in each section. For each respondent, correct responses were summed up to give rise to a total knowledge and practice score. Then, the mean score for each section was analyzed with descriptive statistics function in SPSS.

To discriminate respondents with adequate theoretical and applicable knowledge and those without, a traditional passing mark of $60 \%$ in the professional medical examination was set in our study (24-26). Respondents who score 6.00 and above were considered "adequate", and those who score 5.99 and below were considered "inadequate". We have a similar understanding that there is no gold standard in standard-setting methods $(24,27,28)$. Hence, the different methodology may yield different passing marks $(17,28)$.

Correlation between knowledge and practice was analyzed using the Pearson correlation coefficient because the data was normally distributed. The correlation coefficient value of less than $0.2,0.2$ to $0.39,0.4$ to $0.59,0.6$ to 0.79 , and 0.8 to 1.0 indicates very weak correlation, weak correlation, moderate correlation, strong correlation, and very strong correlation respectively. 
Point estimation from the general population mean with a lower and upper bound of 95\% confidence interval was calculated. Therefore, $p<0.05$ was considered to be statistically significant.

\section{Results}

\section{Demographic Characteristics}

Forty-eight ERs were enrolled in the study. The respondents' age ranged from 26 to 32 years old (Table 1). The median (IQR) age of respondents was 27 (1) years old. The predominant gender of the respondents was female (70.8\%). The duration of medical service among respondents ranged from 12 months to 52 months. The median (IQR) duration of respondents' medical service was 21 (8.8) months. The respondents' duration of ED service ranged from 14 days to 28 months. The median (IQR) years of experience in ED was 3 (3.5) months. Among 48 respondents, only one of them had formal training in CW application.

\section{Capnography: Knowledge Score}

The mean score of overall respondents' knowledge ( \pm SD) was $5.69 \pm 1.82$. The number of respondents who scored above $60 \%$ was $62.5 \%$ (Table 2). Item K3a had the highest percentage of correct response (100\%), while item K2a had the lowest correct response percentage (33.3\%) (Figure 1).

\section{Capnography: Practice Score}

The mean score of respondent skill/practicing ability was $4.40 \pm 1.81$. The number of respondents who scored above $60 \%$ was 29.2\% (Table 2). Five out of 10 items had more than $50 \%$ correct responses (Figure 2). Item P2 had the highest percentage of correct responses (64.4\%), while item P8 had the lowest correct response percentage (4.2\%).

\section{Correlation Between Knowledge and Practice Score}

There was a weak and non-significant correlation between the two variables, $r=0.19, p=0.20$.

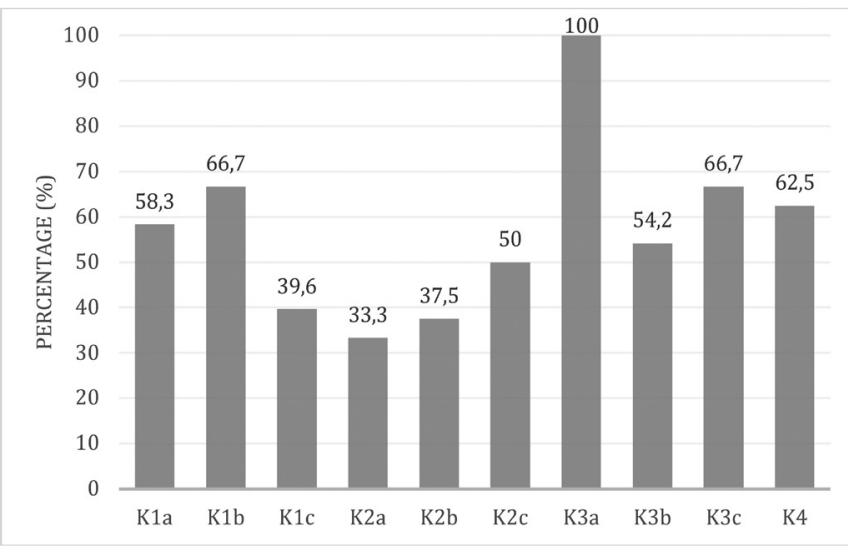

Figure 1. The correct response in the knowledge section

Y-axis/percentage (\%): percentage of respondents answered correctly. $\mathrm{X}$-axis/item: a total of 10 items, starts from item K1a and ends with item K4. Item K3a had the highest percentage of respondents who answered correctly (100\%), while item K2a had the lowest percentage of respondents who answered correctly (33.3\%).

\begin{tabular}{|l|l|l|}
\hline Table 1. Characteristics of respondents & Mdn & \multicolumn{1}{|l|}{ IQR } \\
\hline Item & 27 & $26.5-27.5$ \\
\hline Age (years) & 21 & $12.2-29.8$ \\
\hline Duration of medical service (months) & 3 & $0-6.5$ \\
\hline Duration of experience in ED (months) & $\mathbf{n}$ & $\%$ \\
\hline Gender & 14 & 29.2 \\
\hline Male & 34 & 70.8 \\
\hline Female & \multicolumn{2}{|l}{} \\
\hline Formal training in capnography application & 1 & 2.1 \\
\hline Yes & 47 & 97.9 \\
\hline No & \multicolumn{2}{|l}{} \\
\hline Mdn: Median, IQR: Interquartile range, ED: Emergency department, n: Number, \%: Percentage & & \\
\hline
\end{tabular}

\begin{tabular}{|l|l|l|}
\hline \multicolumn{2}{|l|}{ Table 2. Adequacy level in knowledge and practice } & Adequate \\
\hline & Inadequate & $30(62.5 \%)$ \\
\hline Knowledge & $18(37.5 \%)$ & $14(29.2 \%)$ \\
\hline Practice & $34(70.8 \%)$ & $14 \%$ \\
\hline Respondents who scored correct responses of $\geq 60 \%$ in each section were considered achieved an adequate level of understanding \\
\hline
\end{tabular}




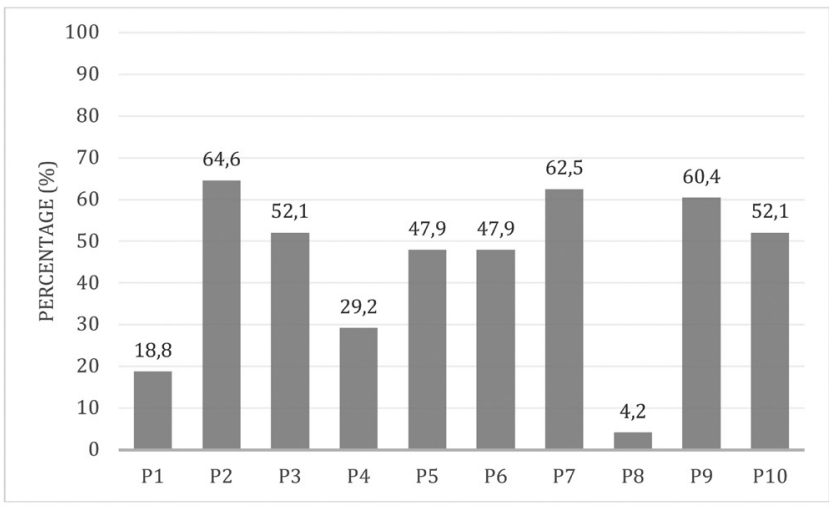

Figure 2. The correct response in the practice section

$\mathrm{Y}$-axis/percentage (\%): percentage of respondents answered correctly. X-axis/item: a total of 10 items, starts from item P1 and ends with item P10. Item P2 had the highest percentage of respondents who answered correctly (64.6\%), while item P8 had the lowest percentage of respondents who answered correctly (4.2\%)

\section{Discussion}

This questionnaire's objective was to assess the knowledge and practice of the ERs towards EtCO interpretation and application because capnography offers great opportunities to improve the quality of treatments and give rescuers feedback on the effectiveness of life-saving procedures, particularly during the management of critically ill patients. However, without adequate knowledge of CW interpretation and application, capnography is just a fancy gadget without purpose. It is necessary to prepare future ERs on the right path of patients' safety and effective practice regarding the CW application.

In our study, the majority of the respondents were junior doctors. The most senior respondent in this study served 4 years in health service and 2 years in ED. There were a few identified reasons for lack of senior ERs. For instance, the diversity/complexity in patients' clinical presentations (trauma, acute surgical, neuropsychiatric, acute medical, domestic violence, child abuse), shift duty, challenges in leave management, and "not knowing what is coming through the doors next" (29). In Malaysia scenario, ERs with a great interest in pursuing their career in Emergency Medicine by joining the master program or fellowship program will serve longer in the ED.

Being a junior ER and working in the overcrowding and unpredictable environment with undifferentiated cases is indeed a great challenge, particularly in making appropriate clinical reasoning and decision making of undifferentiated illness from different genders and age groups. ED clinician's responsibilities that exceed the junior ERs' capabilities may lead to stress, hence providing substandard management to patients.
In most of ED in Malaysia, the severity of the patient's condition was categorized into three zones, i.e., red zone (critical), yellow zone (semi-critical), and green zone (non-critical). Red zone and yellow zone patients suffered from life-threatening and potentially life-threatening conditions whereby the capnography evaluation is indicated in the measurement of adequacy of alveolar ventilation, airway integrity, cardiopulmonary function, and ventilator function. ED administrator tends to locate the junior ERs to the non-critical zones for them to familiarise with the new challenges, new workplace environment, and different type of cases. Therefore, it was not surprised if the respondents had inadequate knowledge of capnography and its application. Few studies revealed that despite the availability of capnography devices, there was a lack of knowledge and skills among emergency medical service providers $(30,31)$.

This study revealed that most respondents (97.9\%) did not receive any formal training in capnography during their undergraduate years and internship period. Probable reasons included $\mathrm{EtCO}_{2}$ is not an important vital sign in Malaysia, it is not widely available throughout the country, and $\mathrm{PaCO}_{2}$ level is available in arterial blood gases test (32-34).

The knowledge score distribution among the ERs of less than 6.0 and above 6.0 was $38 \%$ and $62 \%$, respectively. Surprisingly, two-thirds of ERs had adequate knowledge of capnography. The mean $( \pm \mathrm{SD})$ score of overall respondents' knowledge was $5.69 \pm 1.82$. All the respondents answered correctly regarding CW's indication during the management of sudden cardiac arrest or CPR (Question K3a). However, three-quarters of them did not answer correctly on the normal range of $\mathrm{EtCO}_{2}$ (Question K2a).

Most ERs had achieved an adequate level in the knowledge section despite limited training, and previous exposure was an interesting finding. There are a few reasons to explain the above findings. In our opinion, the CW has a simple structure or shape, and the information is easily deduced if the respondents understood the respiratory system, carbon dioxide transport, and cellular metabolism. A study by lyer et al. (35) in 2015 demonstrated after mild exposure and education, nearly all the respondents were able to achieve basic understandings and adequate knowledge in $\mathrm{EtCO}_{2}$ readings. Moreover, in our $E D, C W$ in different clinical scenarios was printed and exhibited on the wall next to the resuscitation zone's monitoring devices. The exhibited printed information provides interpretation assistance of the waveform and troubleshooting assistance to the doctors on duty. Interpretations and use of CW were discussed briefly during relevant topics in continuous medical education (CME) sessions, e.g., cardiac arrest, emergency intubation, and post-intubation care. ERs may also acquire knowledge on CW 
during attending relevant courses, e.g., advanced cardiac life support (ACLS) and mechanical ventilator workshop. And not to mention the role of emergency physicians who discussed the capnography's advantages and disadvantages during their ward round or bedside teaching.

In this study, most ERs (71\%) had a practical score of less than 6.0, which is considered insufficient practical skill regarding response to abnormal CW. The mean ( \pm SD) score of overall respondents in the practice section was $4.40 \pm 1.81$. Most of the questions in the practice section were answered incorrectly by the ERs. Only $64 \%$ of respondents answered correctly for re-intubation in the event of continuous flat waveform tracings post-intubation, and only $4 \%$ of respondents able to recognize the leaking endotracheal tube and choose to re-intubate patients.

In our hospital setting, CW only available in the form of sidestream device for monitoring intubated patients in the resuscitation zone. Limited working experience in the resuscitation zone, less exposure to the practical use of waveform, and it was not consistently applied to the patient may contribute to the low competency level in the practice section of our study (36-38). The inconsistent use of CW among clinical staff in acute care settings, despite emerging evidence of CW monitoring in improving patient safety, is a discouraging fact. Lack of awareness and specific knowledge deficits on the importance of CW in clinical practice contribute to capnography application failure (39). The planned organizational effort for implementation plays a role in promoting CW $(40,41)$. In the UK, the $4^{\text {th }}$ national audit project of the Royal College of Anaesthetists and Difficult Airway Society (NAP4) recommended CW monitoring during intubation in the ED setting (42).

Competence is the acquisition of knowledge, skills, and abilities at a level of expertise sufficient to perform in an appropriate work setting. In simple words, knowledge and practice should always go hand in hand (30). Our study demonstrated an extremely weak correlation between the interpretation knowledge of CW and its clinical application. In other words, the respondent's knowledge was not reflected in their practice. Reasons for the insignificant correlation could be multifactorial. Lack of policy, lack of motivation, and inadequate training may be part of the reasons (43). We believe that the interpretation of CW is related to pre-existing theoretical knowledge but the clinical application requires practice and experience, hence the correlation was weak.

Interestingly, this finding was similar to a study conducted by Wylie et al. (31) in 2019, except the studied population were paramedics. The study demonstrated that pre-hospital care staff achieved high CW knowledge scores but low scores in CW applications. However, the attributing factors were not studied (31).

\section{Recommendations}

Our study showed different results from other studies $(30,44)$. It was also contrary to common study findings that higher knowledge scores were associated with higher practice scores (45-47), and vice versa. Hence, different strategies are required to improve the competency of ERs in CW. The training program is of utmost importance: Czyż et al. (30) in 2018 demonstrated that emergency medical services providers who received training in CW achieved significantly higher scores than those who did not receive training.

CME sessions regarding basic and advanced usage of CW should be organized at the departmental level. The knowledge of CW should be incorporated into other related courses, e.g., ACLS. Bedside teaching should be encouraged and continued. In particular, a specific indication of CW can be discussed, e.g., during CPR, with the addition of current evidence, benefits, and data interpretations rather than a general overview. The discussions will then serve as a gateway to other applications with CW (41). Diagram, poster, or flip chart regarding CW should be made available in the resuscitation zone. The logbook should include CW applications as one of the core competencies in the emergency residency program.

At the organizational level, the standard operating procedure of positive ventilated patient care should include CW monitoring. $\mathrm{EtCO}_{2}$ level should be monitored in all positive ventilated patients and documented in medical records or charts $(48,49)$. Stocks of capnography should be made available and easily accessible in the department (41).

\section{Study Limitations}

There are limitations to this study. The methodology and study design limit the sample, and the results cannot be generalized to other departments, e.g., ICU care settings, or different posts in emergency care settings, e.g., staff nurses. The closedended type instrument limits its ability to explore the reason for different competency levels in the knowledge and practice section. The difficulty level of each item and item discrimination were not analyzed in this study. The lack of respondents with previous training and experience in $\mathrm{CW}$ also makes studying the correlation between them and knowledge with practice difficult. We do not know whether senior ERs would have produced different outcomes in this study. Future studies should involve a different level of expertise or center and further validation of the instrument. 


\section{Conclusion}

The knowledge in CW among ERs, particularly junior residents, was sufficient. However, the appropriate response towards the abnormal finding of CW was questionable. Strategies should be formulated to enhance their knowledge and training on the daily application of CW, with the ultimate goal of improving patient safety.

\section{Ethics}

Ethics Committee Approval: This study was approved by the Malaysia Medical Research and Ethics Committee (MREC) through National Medical Research Register (ID: NMRR-19-1763-49223) on July $19^{\text {th }}, 2019$.

Informed Consent: Written consent was obtained from emergency residents working in the emergency department, Hospital Melaka who fulfiled inclusion criteria.

Peer-review: Externally peer-reviewed.

\section{Author Contributions}

Concept: R.C.C, R.A., M.I.Z., M.F.Y., Design: R.C.C, R.A., M.I.Z., M.F.Y., Supervision: C.R.C, R.A., M.I.Z., M.F.Y., Resources: R.C.C, R.A., M.F.Y., Materials: R.C.C, R.A., Data Collection and/or Processing: R.C.C, R.A., M.F.Y., Analysis and/or Interpretation: R.C.C, R.A., M.I.Z., Literature Search: R.C.C, R.A., M.F.Y., Writing: R.C.C, R.A., M.I.Z., M.F.Y., Critical Review: R.C.C, R.A., M.I.Z.

Conflict of Interest: There is no conflict of interest.

Financial Disclosure: The author(s) received no financial support or funding for this research, authorship and/or publication of this article.

\section{References}

1. Whitaker DK. Time for capnography - everywhere. Anaesthesia. 2011;66:5449 .

2. Kodali BS. Capnography outside the operating rooms. Anesthesiology. 2013;118:192-201.

3. Nassar BS, Schmidt GA. Capnography During Critical Illness. Chest. 2016:149:576-85.

4. Manifold CA, Davids N, Villers LC, Wampler DA. Capnography for the nonintubated patient in the emergency setting. J Emerg Med. 2013;45:62632.

5. Ward KR, Yealy DM. End-tidal carbon dioxide monitoring in emergency medicine, Part 1: Basic principles. Acad Emerg Med. 1998;5:628-36.

6. Committee on Standards and Practice Parameters. Standards for Basic Anesthetic Monitoring. American Society of Anesthesiologists. Available at.http://www.asahq.org/quality-and-practice-management/standardsguidelines-and-related-resources/standards-for-basic-anestheticmonitoring. Accessed: March 14, 2018.

7. Adams L, Butas S, Spurlock D Jr. Capnography (ETCO2), respiratory depression, and nursing interventions in moderately sedated adults undergoing transesophageal echocardiography (TEE). J Perianesth Nurs. 2015;30:14-22.
8. Burton JH, Harrah JD, Germann CA, Dillon DC. Does end-tidal carbon dioxide monitoring detect respiratory events prior to current sedation monitoring practices? Acad Emerg Med. 2006;13:500-4.

9. Richardson M, Moulton K, Rabb D, Kindopp S, Pishe T, Yan C, et al. Capnography for Monitoring End-Tidal CO2 in Hospital and Pre-hospital Settings: A Health Technology Assessment. Ottawa (ON):Canadian Agency for Drugs and Technologies in Health. 27 May 2016.

10. Nagurka R, Bechmann S, Gluckman W, Scott SR, Compton S, Lamba S. Utility of initial prehospital end-tidal carbon dioxide measurements to predict poor outcomes in adult asthmatic patients. Prehosp Emerg Care. 2014;18:180-4.

11. Link MS, Berkow LC, Kudenchuk PJ, Halperin HR, Hess EP, Moitra VK, et al. Part 7: Adult Advanced Cardiovascular Life Support: 2015 American Heart Association Guidelines Update for Cardiopulmonary Resuscitation and Emergency Cardiovascular Care. Circulation. 2015;132(18 Suppl 2):S444-64.

12. Soar J, Nolan JP, Böttiger BW, Perkins GD, Lott C, Carli P, et al. European Resuscitation Council Guidelines for Resuscitation 2015: Section 3. Adult advanced life support. Resuscitation. 2015;95:100-47.

13. Kolar M, Krizmaric M, Klemen P, Grmec S. Partial pressure of end-tidal carbon dioxide successful predicts cardiopulmonary resuscitation in the field: a prospective observational study. Crit Care. 2008;12:R115.

14. Bujang MA, Baharum N. Sample size guideline for correlation analysis. World Jornal of Social Science Research. 2016;3:37-46.

15. Guenther WC. Desk Calculation of Probabilities for the Distribution of the Sample Correlation Coefficient. Am Stat. 1977;31:45-8.

16. Artino AR Jr, La Rochelle JS, Dezee KJ, Gehlbach H. Developing questionnaires for educational research: AMEE Guide No. 87. Med Teach. 2014;36:463-74.

17. Boursicot KA, Roberts TE, Pell G. Standard setting for clinical competence at graduation from medical school: a comparison of passing scores across five medical schools. Adv Health Sci Educ Theory Pract. 2006;11:173-83.

18. Lynn MR. Determination and quantification of content validity. Nurs Res. 1986;35:382-5.

19. Rubio DM, Berg-Weger M, Tebb SS, Lee ES, Rauch S. Objectifying content validity: Conducting a content validity study in social work research. Social work research. 2003;27:94-104.

20. Davis LL. Instrument rewiew: Getting the most from a panel of experts. Appl Nurs Res. 1992;5:194-7.

21. Waltz CF, Strickland OL, Lenz ER. Measurement in nursing and health research. 3rd ed. New York: Springer; 2005.

22. Portney LG, Watkins MP. Foundations of clinical research: applications to practice (Vol. 892). Upper Saddle River, NJ: Pearson/Prentice Hall; 2009.

23. Koo TK, Li MY. A Guideline of Selecting and Reporting Intraclass Correlation Coefficients for Reliability Research. J Chiropr Med. 2016;15:155-63.

24. Ben-David MF. AMEE Guide No. 18: Standard setting in student assessment. Medical Teacher. 2000;22:120-30.

25. Liu M, Liu KM. Setting pass scores for clinical skills assessment. Kaohsiung J Med Sci. 2008;24:656-63

26. Tekian A, Norcini J. Overcome the $60 \%$ passing score and improve the quality of assessment. GMS Z Med Ausbild. 2015;32:Doc43.

27. Kane MT, Crooks TJ, Cohen AS. Designing and Evaluating Standard-Setting Procedures for Licensure and Certification Tests. Adv Health Sci Educ Theory Pract. 1999;4:195-207.

28. Downing SM, Tekian A, Yudkowsky R. Procedures for establishing defensible absolute passing scores on performance examinations in health professions education. Teach Learn Med. 2006;18:50-7.

29. Rosen B, Rosen P, Schofer J, Asher S, Wald D, Cheaito MA, et al. Is Emergency Medicine the Right Choice for Me? J Emerg Med. 2019;56:e35-8. 
30. Czyż R, Leśkiewicz M, Czyż I. Knowledge and skills toward capnometry and capnography among Emergency Medical Service providers. J Educ, Health Sport. 2018;8:121-7.

31. Wylie C, Welzel T, Hodkinson P. Waveform capnography in a South African prehospital service: Knowledge assessment of paramedics. Afr J Emerg Med. 2019;9:96-100.

32. Zwerneman K. End-tidal carbon dioxide monitoring: a VITAL sign worth watching. Crit Care Nurs Clin North Am. 2006;18:217-25.

33. Evans T, Laborato L, Lord J. Capnography the seventh vital sign. RT for Decision Makers in Respiratory Care. 2008;21:30-3.

34. Hunter CL, Silvestri S, Ralls G, Bright S, Papa L. The sixth vital sign: prehospital end-tidal carbon dioxide predicts in-hospital mortality and metabolic disturbances. Am J Emerg Med. 2014;32:160-5.

35. Iyer NS, Koziel JR, Langhan ML. A qualitative evaluation of capnography use in paediatric sedation: perceptions, practice and barriers. J Clin Nurs. 2015;24:2231-8

36. Deiorio NM. Continuous end-tidal carbon dioxide monitoring for confirmation of endotracheal tube placement is neither widely available nor consistently applied by emergency physicians. Emerg Med J. 2005;22:490-3.

37. Ilko SA, Vakkalanka JP, Ahmed A, Evans DA, House HR, Mohr NM. End-tidal $\mathrm{CO}_{2}$ Monitoring is Available in Most Community Hospitals in a Rural State: A Health System Survey. West J Emerg Med. 2019;20:232-6.

38. Turle S, Sherren PB, Nicholson S, Callaghan T, Shepherd SJ. Availability and use of capnography for in-hospital cardiac arrests in the United Kingdom. Resuscitation. 2015;94:80-4.

39. Cook TM, Woodall N, Frerk C. A national survey of the impact of NAP4 on airway management practice in United Kingdom hospitals: closing the safety gap in anaesthesia, intensive care and the emergency department. $\mathrm{Br}$ J Anaesth. 2016;117:182-90.

40. Obstfelder A, Engeseth KH, Wynn R. Characteristics of successfully implemented telemedical applications. Implement Sci. 2007;2:25.
41. Langhan ML, Kurtz JC, Schaeffer P, Asnes AG, Riera A. Experiences with capnography in acute care settings: a mixed-methods analysis of clinical staff. J Crit Care. 2014;29:1035-40.

42. Cook TM, Woodall N, Harper J, Benger J; Fourth National Audit Project. Major complications of airway management in the UK: results of the Fourth National Audit Project of the Royal College of Anaesthetists and the Difficult Airway Society. Part 2: intensive care and emergency departments. $\mathrm{Br}$ J Anaesth. 2011;106:632-42.

43. Bowles TM, Freshwater-Turner DA, Janssen DJ, Peden CJ; RTIC Severn Group. Out-of-theatre tracheal intubation: prospective multicentre study of clinical practice and adverse events. Br J Anaesth. 2011;107:687-92.

44. Kiekkas P, Stefanopoulos N, Konstantinou E, Bakalis N, Aretha D. Development and psychometric evaluation of an instrument for the assessment of nurses' knowledge on capnography. Collegian. 2016;23:39-46.

45. Ahayalimudin N, Osman NN. Disaster management: Emergency nursing and medical personnel's knowledge, attitude and practices of the East Coast region hospitals of Malaysia. Australas Emerg Nurs J. 2016;19:203-9.

46. Pouraghaei M, Sadegh Tabrizi J, Moharamzadeh P, Rajaei Ghafori R, Rahmani F, Najafi Mirfakhraei B. The Effect of Start Triage Education on Knowledge and Practice of Emergency Medical Technicians in Disasters. J Caring Sci. 2017;6:119-25.

47. Sharifi Y, Nikravan Mofard M, Jamsahar M, Nasiri M, Safari M. Knowledge, Attitude, and Practice of Emergency Medical Services Staff in Bleeding Control of Trauma Patients; a Cross sectional Study. Arch Acad Emerg Med. 2020;8:e11.

48. Gulube SM, Wynchank S. Telemedicine in South Africa: success or failure? J Telemed Telecare. 2001;7 (Suppl) 2:47-9.

49. LaMonte MP, Bahouth MN, Hu P, Pathan MY, Yarbrough KL, Gunawardane $\mathrm{R}$, et al. Telemedicine for acute stroke: triumphs and pitfalls. Stroke. 2003;34:725-8. 


\section{Appendix 1}

THE ASSESSMENT OF END-TIDAL CAPNOGRAPHY WAVEFORMS INTERPRETATION AND ITS CLINICAL APPLICATION FOR EMERGENCY RESIDENTS IN Malaysia: A CROSS-SECTIONAL STUDY

\section{Section A: Demographics}

Age: Gender: Male/Female

Years of medical service: year/s month/s Years of experience in the emergency department: year/s month/s Previous training in capnography waveforms: Yes/No Years of experience in capnography waveforms monitoring:

\section{Section B: Knowledge}

This section consists of 4 questions related to end-tidal capnography waveforms interpretation. Select the correct answer.

1. Diagram below shows a normal end-tidal $\mathrm{CO}_{2}$ capnography waveform tracings. AB-BC-CD-DE represents phases in a waveform produced by inspiration and expiration.

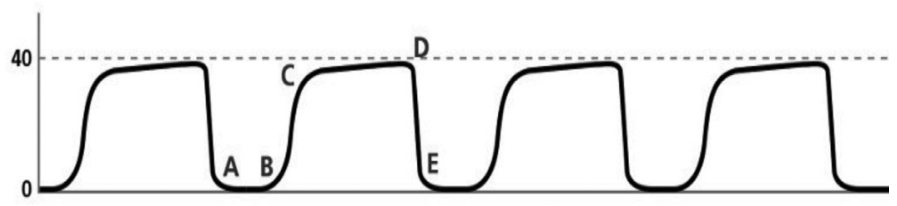

Please match the following:

\begin{tabular}{|l|l|l|l|}
\hline Alveolar plateau & Early inspiration & Expiration & Early expiration \\
\hline Late inspiration & Late expiration & Alpha angle & End-tidal $\mathrm{CO}_{2}$ \\
\hline
\end{tabular}

a. $D$ represents

b. CD represents

c. DE represents

2. Please tick your answer

\begin{tabular}{|l|l|l|l|l|}
\hline & Regarding $\mathrm{EtCO}_{2}$ level & True & False & Unsure \\
\hline a. & The normal range is $30-40 \mathrm{mmHg}$ & & & \\
\hline b. & Hypotension decreases $\mathrm{EtCO}_{2}$ level & & & \\
\hline c. & Hyperpyrexia increases $\mathrm{EtCO}_{2}$ level & & & \\
\hline
\end{tabular}

3. Please tick your answer

\begin{tabular}{|l|l|l|l|l|}
\hline & $\begin{array}{l}\text { Indications of capnography } \\
\text { waveform monitoring in the } \\
\text { emergency department include }\end{array}$ & True & False & Unsure \\
\hline a. & Cardiopulmonary resuscitation & & & \\
\hline b. & Ischemic stroke & & & \\
\hline c. & Dengue fever & & & \\
\hline
\end{tabular}

4. A 50 years old patient was intubated and sedated in the resuscitation zone. End-tidal capnography $\left(\mathrm{EtCO}_{2}\right)$ was applied and produces the capnography waveform, as shown below. What are the possible causes?

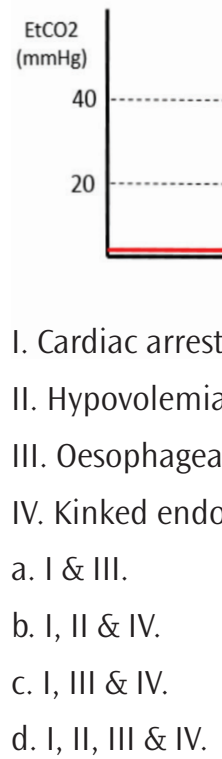

\section{Section C: Practice}

This section consists of 10 questions related to capnography waveform simulation and application. Select the correct answer.

1. A 50 years old gentleman had a cardiac arrest in the emergency department. Cardiopulmonary resuscitation (CPR) commenced immediately, and the patient was intubated. Endtidal capnography $\left(\mathrm{EtCO}_{2}\right)$ applied. Tracings, as shown below with ongoing CPR.

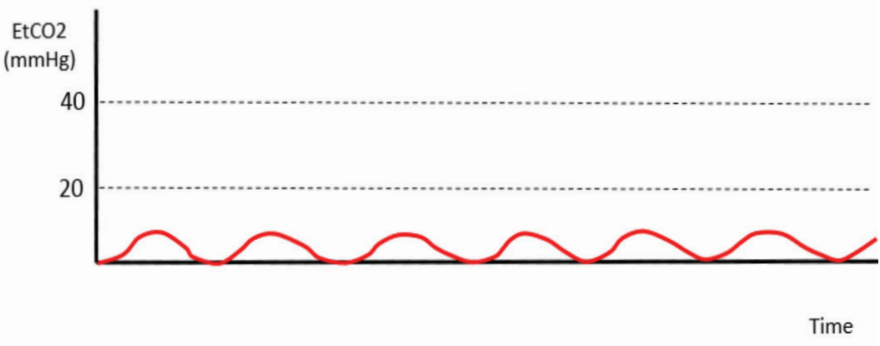

What is the most appropriate action?

a. Continue chest compression.

b. Switch compression provider.

c. Terminate chest compression.

d. Increase the volume of bagging.

2. A 60 years old gentleman had a sudden cardiac arrest. Cardiopulmonary resuscitation (CPR) commenced, and the 
patient was intubated. End-tidal capnography $\left(\mathrm{EtCO}_{2}\right)$ applied. Capnography waveform tracings, as shown below with ongoing chest compression.

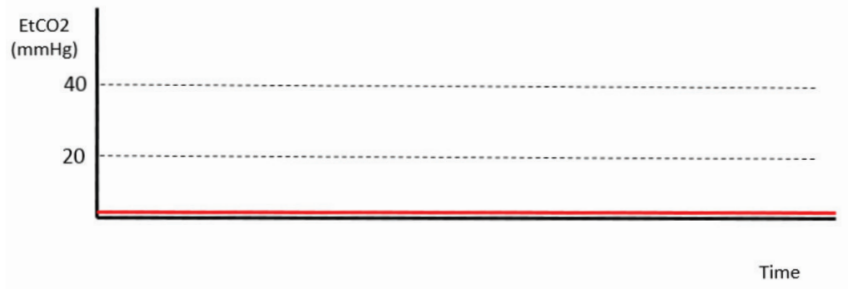

What is the most appropriate action?
a. 5 point auscultation of the lungs.
b. Readjust ETT depth.
c. Re-intubate patient.
d. Switch compressor.

3. A 30 years old patient was intubated during cardiopulmonary resuscitation (CPR). End-tidal capnography $\left(\mathrm{EtCO}_{2}\right)$ applied. Capnography waveform, as shown below, was noted during chest compression.

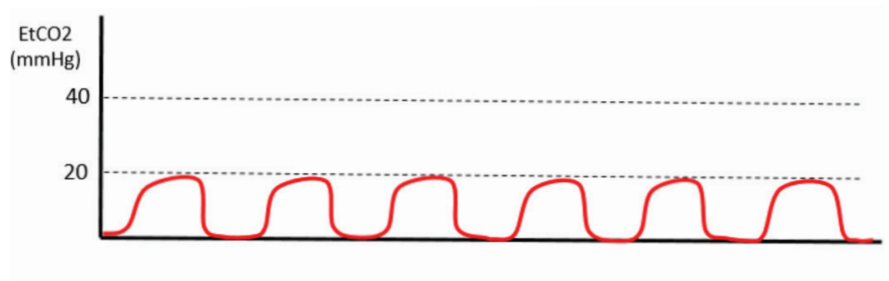

What is the most appropriate action?
a. Perform lung auscultation.
b. Continue high-quality CPR.
c. Increase the rate of bagging.
d. Switch chest compressor.

4. A 50 years old gentleman had a sudden cardiac arrest. Cardiopulmonary resuscitation (CPR) commenced. The patient was intubated, and end-tidal capnography $\left(\mathrm{EtCO}_{2}\right)$ was applied. High-quality Cardiopulmonary resuscitation (CPR) was performed for 20 minutes and remains asystole during pulse check. The capnography waveform below was noted persistently throughout the 20 minutes of chest compression.

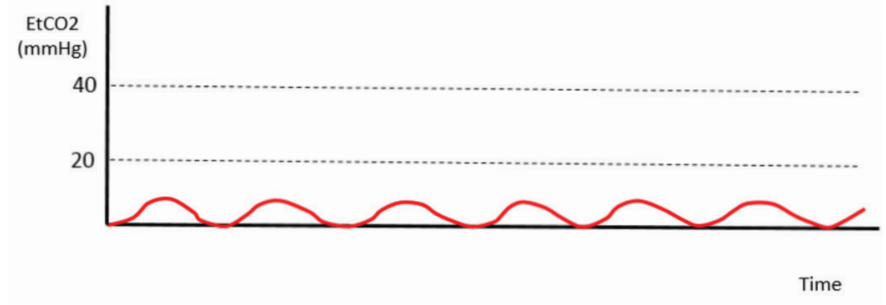

What is the most appropriate action?

a. Continue high-quality CPR.

b. Switch chest compressor.

c. Increase the rate of bagging.

d. Termination of resuscitation.

5. A 50 years old lady had a sudden cardiac arrest. Cardiopulmonary resuscitation (CPR) commenced immediately, and she was intubated. End-tidal capnography $\left(\mathrm{EtCO}_{2}\right)$ applied. High-quality CPR was performed for 20 minutes, and you noticed capnography waveform changes, as shown below.

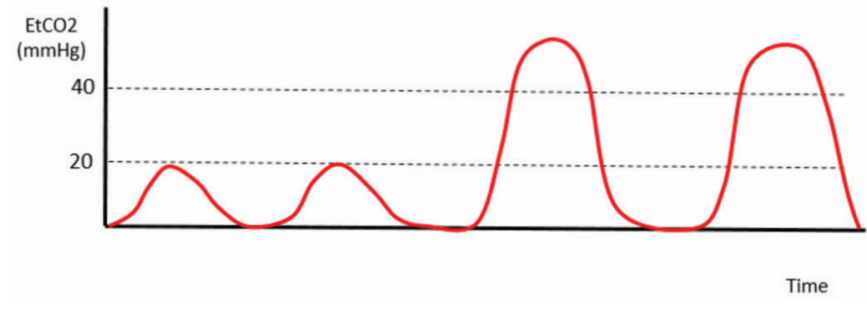

What is the most appropriate action?

a. Pulse check.

b. Increase the rate of bagging.

c. Decrease the volume of bagging.

d. Termination of resuscitation.

6. A $70 \mathrm{~kg}$ patient with an isolated severe traumatic brain injury was intubated. Ventilator connected and end-tidal capnography $\left(\mathrm{EtCO}_{2}\right)$ applied. Ventilator setting: mode SIMV, tidal volume $500 \mathrm{ml}$, rate 22 , IE ratio 1:2, FiO2 1.0. The capnography waveform is shown below.

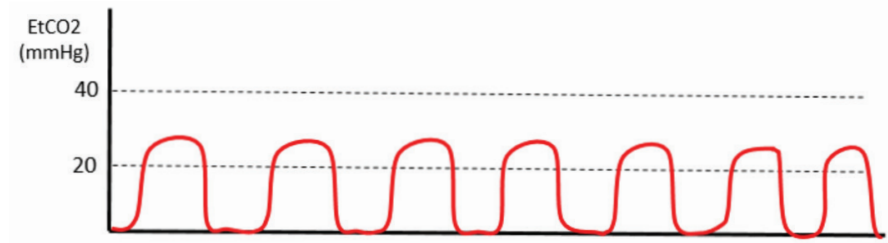


What is the most appropriate action?
a. Reduce the ventilation rate.
b. Increase tidal volume.
C. Prolonged I: E ratio.
d. Reduce $\mathrm{FiO}_{2}$.

7. A 65 years old patient was intubated for poor respiratory effort and hypoxia secondary to severe pneumonia. The capnography waveform is shown below.

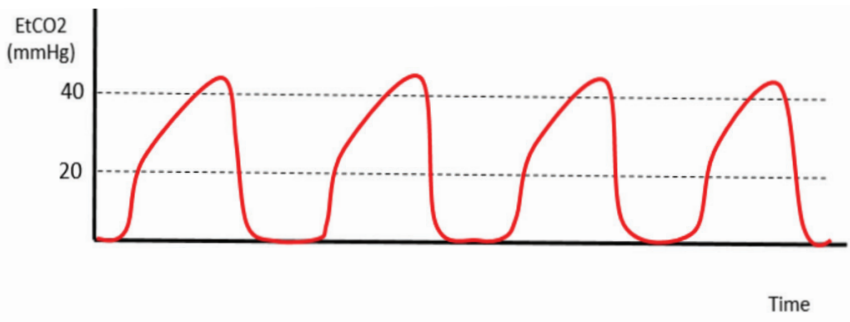

What is the most appropriate action?
a. Re-intubate the patient.
b. Increase the tidal volume setting.
c. Administer bronchodilator therapy.
d. Check the plateau pressure.

8. A 30 years old male patient was intubated in the resuscitation zone. The ventilator was connected, and end-tidal capnography $\left(\mathrm{EtCO}_{2}\right)$ was applied. Endotracheal tube (ETT) size $8 \mathrm{~mm}$ was used, anchored at $24 \mathrm{~cm}$, and the pilot balloon inflated with $10 \mathrm{cc}$ of air (ETT cuff pressure measured $25 \mathrm{cmH}_{2} \mathrm{O}$ ). The capnography waveform is shown below.

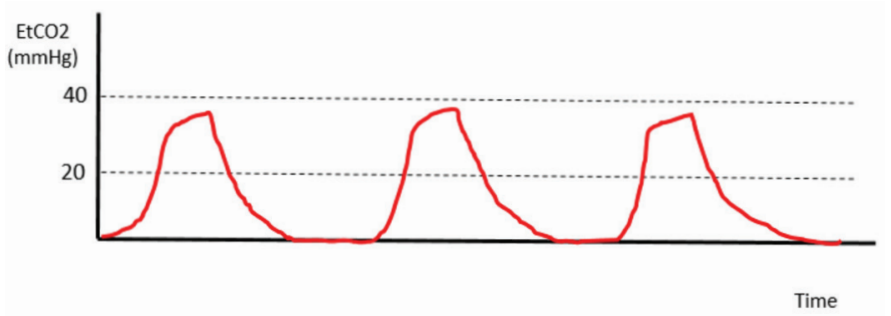

What is the most appropriate action?
a. Readjust ETT depth to $22 \mathrm{~cm}$.
b. Administer bronchodilator therapy.
c. Re-intubate with the same size endotracheal tube.
d. Inflate the pilot balloon with another 10cc of air.

9. A 25 years old gentleman had a severe maxillofacial injury. He was intubated and ventilated. End-tidal capnography (EtCO2) applied. Ventilator setting: mode SIMV, tidal volume (Vt) 480ml, rate 10 , IE ratio 1:2, FiO2 1.0. The capnography waveform is shown below.

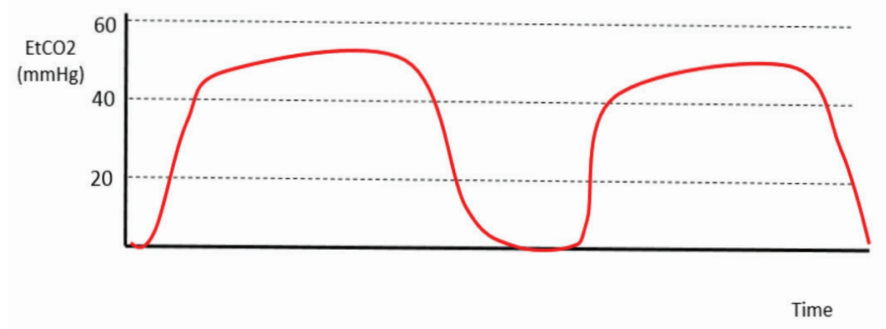

What is the most appropriate action?

a. Increase the I: E ratio to 1:3.

b. Increase Vt to $600 \mathrm{ml}$.

c. Increase rate to 14 .

d. Switch to CMV mode.

10. A 25 years old gentleman was intubated using an endotracheal tube (ETT) diameter of $8 \mathrm{~mm}$, anchored at $28 \mathrm{~cm}$, and the pilot balloon inflated to achieve ETT cuff pressure of $20-30 \mathrm{cmH}_{2} \mathrm{O}$. The ventilator is connected, and end-tidal capnography $\left(\mathrm{EtCO}_{2}\right)$ was applied. Capnography waveform tracings, as shown below.

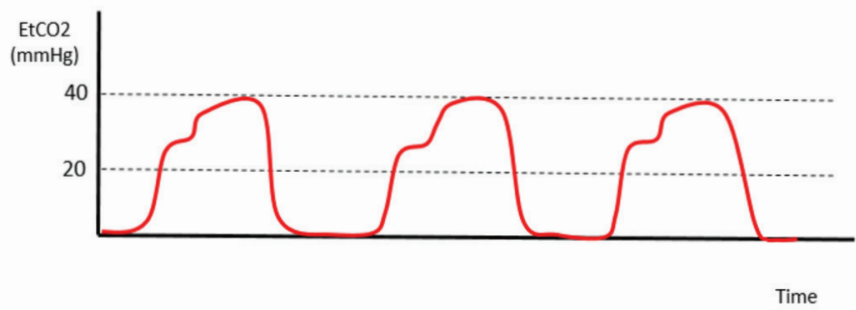

What is the most appropriate action?

a. Re-intubate with ETT size $7 \mathrm{~mm}$.

b. Remove 5 cc of air from the ETT cuff.

C. Administer bronchodilator therapy.

d. Readjust the depth of ETT.

- End of questionnaire - 